\title{
Retrospective analysis of HF detection in city hospitals of Bishkek in three-year study (2016-2018)
}

\author{
Taalaibek Z. Kudaiberdiev, Akylbek A. Zhooshev, Damirbek A. Abibillaev
}

Scientific-Research Institute of Heart Surgery and Organ Transplantation, Bishkek, Kyrgyzstan

\begin{abstract}
In this article, we analyzed prevalence of heart failure in patients visited cardiology departments of secondary level hospitals of Bishkek city, Kyrgyz Republic.
\end{abstract}

Key words: heart failure, prevalence, retrospective analysis, coronary heart disease, secondary healthcare level

(Heart, Vessels and Transplantation 2019; 3: doi)

\section{Introduction}

$\mathrm{HF}$ is a clinical syndrome characterized by typical symptoms (e.g. breathlessness, ankle swelling and fatigue) that may be accompanied by signs (e.g. elevated jugular venous pressure, pulmonary crackles and peripheral oedema) caused by a structural and/or functional cardiac abnormality, resulting in a reduced cardiac output and/or elevated intracardiac pressures at rest or during stress $(1,2)$.

The Framingham criteria for the diagnosis of heart failure consists of the concurrent presence of either two major criteria or one major and two minor criteria from the clinical point of view (1). The New York Heart Association (NYHA) classification system categorizes heart failure on a scale of I to IV on the basis of physical activity (3). The American College of Cardiology/American Heart Association (ACC/AHA) staging system is defined by the four stages according to presence of structural heart disease (4).

The list of causes responsible for presentation of a patient with heart failure exacerbation is very long, and searching for the proximate cause to optimize therapeutic interventions is important. From a clinical standpoint, classifying the causes of heart failure into the following four broad categories is useful: underlying causes, precipitating causes, fundamental causes and genetic cardiomyopathies (5).
The prevalence of heart failure increases with age (6). In general, the mortality following hospitalization for patients with heart failure is $10.4 \%$ at 30 days, $22 \%$ at 1 year, and $42.3 \%$ at 5 years, despite marked improvement in medical and device therapy (7-11).

\section{Methods}

The prevalence of heart failure among three clinical hospitals of Bishkek city retrospectively analyzed on the basis of underlying cardiac pathology, from 2016 to 2018 years.

\section{Results \\ Prevalence of HF in city hospital №1}

Total number of patients registered in three years (2016-2018) is 438. Actual number of visited patients assumed as higher, though other hospital registries has shown relatively more cases. Low quantity of patients in this institution may be presumably associated with lack of registration due to closing of hospital for renovation for several periods. Among underlying conditions (Table 1 and Fig. 1), coronary artery disease (CAD) with various forms prevailed: $83,6 \%$ for 2016; 80,6\% for 2017 and 74,7\% all cases for 2018 . The total percentage of CAD was $80,8 \%$ for three years. The least detected underlying disease was myocarditis with $0,9 \%$ incidence for three years.

Address for Correspondence: Damirbek A. Abibillaev, Scientific-Research Institute of Heart Surgery and Organ

Transplantation, Bishkek, Kyrgyzstan

Received: 13.03.2019 Accepted: 05.04.2019

Copyright@2019 Heart, Vessels and Transplantation 
Table 1. The prevalence of heart failure in city hospital N1

\begin{tabular}{|l|l|c|c|c|}
\hline & Underlying conditions & \multicolumn{2}{l|}{ Patient numbers } \\
\cline { 3 - 5 } & & $\mathbf{2 0 1 8}$ & $\mathbf{2 0 1 7}$ & $\mathbf{2 0 1 6}$ \\
\hline A. & Rheumatic heart disease & 8 & 6 & 12 \\
\hline B. & $\begin{array}{l}\text { CAD: acute MI, unstable angina, } \\
\text { stable coronary heart disease, } \\
\text { chronic ischemic cardiomyopathy }\end{array}$ & 80 & 79 & 195 \\
\hline C. & Cardiomyopathies & - & 2 & - \\
\hline D. & Myocarditis & 3 & & 1 \\
\hline E. & Essential hypertension & 16 & 11 & 25 \\
\hline & Total & $\mathbf{1 0 7}$ & $\mathbf{9 8}$ & $\mathbf{2 3 3}$ \\
\hline
\end{tabular}

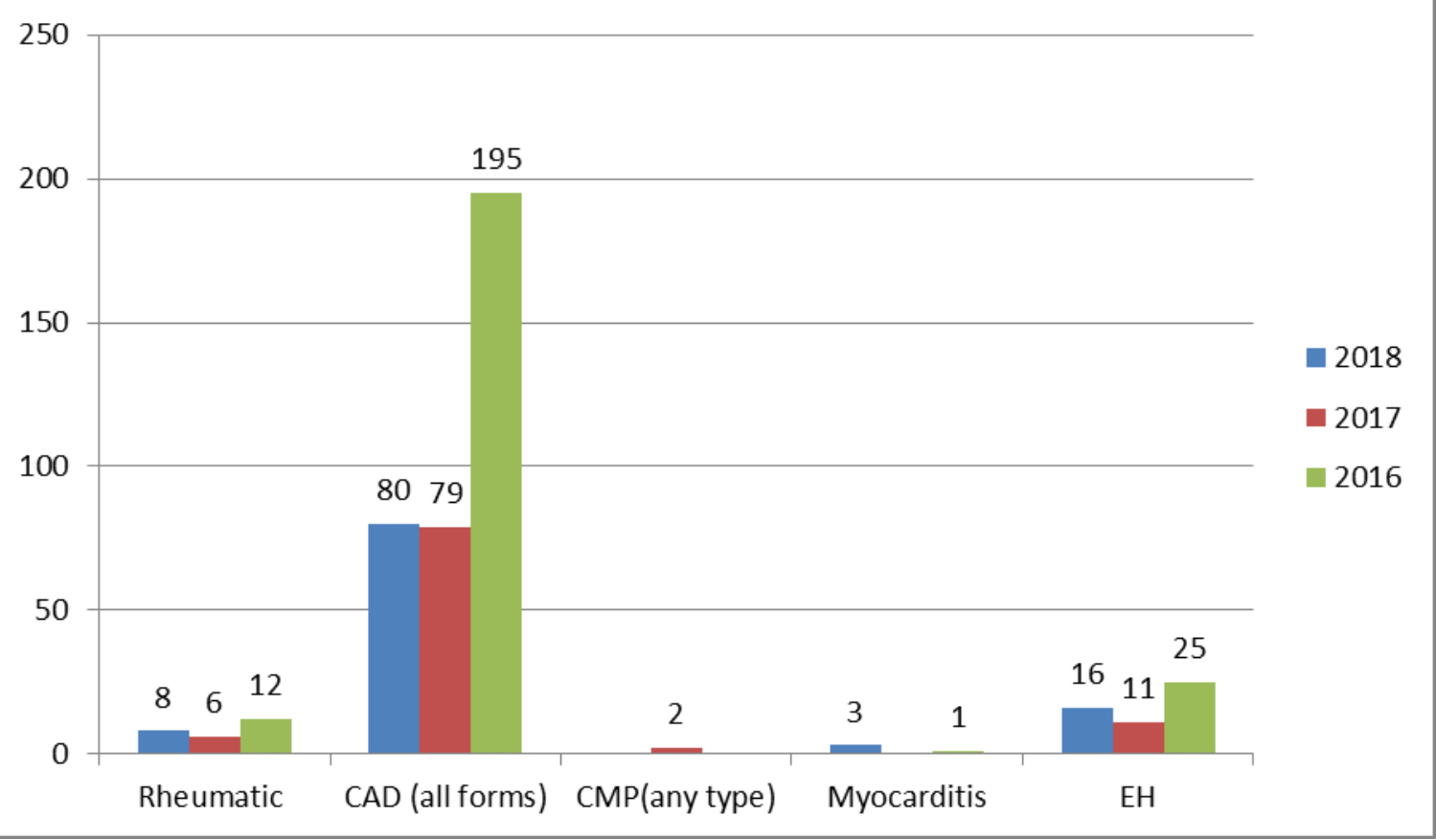

Figure 1. The prevalence of heart failure in city hospital N1 


\section{Prevalence of HF in city hospital №6}

Total number of patients in timeline 2016-2018 registered as 5247. From this clinical data, we can see more realistic reflection of patient registry. As can be seen from Table 2 and Figure 2, prevalence of disease remains in plateau, without gradual dynamics. It probably shows constant admission of patients over periods. Among underlying conditions, as in previews hospital, CAD with various forms prevailed: $91,9 \%$ for 2016; 90,9\% 90,8\% for 2017 and all cases for 2018. The total percentage of CAD was $91,2 \%$ for three years. In structure of $C A D$, unstable angina prevailed: $53,25 \%$ of coronary disorders registered for three years. This hospital registered also non-cardiac conditions complicated or concomitant heart failure conditions, such as cardio-renal syndrome.

\begin{tabular}{|c|c|c|c|c|}
\hline & \multirow[t]{2}{*}{ Underlying conditions } & \multicolumn{3}{|c|}{ Patient numbers } \\
\hline & & 2018 & 2017 & 2016 \\
\hline A. & STEMI/ NSTEMI (non-Q AMI) & 78 & 108 & 109 \\
\hline B. & $\begin{array}{l}\text { Acute cerebrovascular event, concomitant heart } \\
\text { failure }\end{array}$ & 1 & 2 & 1 \\
\hline C. & Chronic rheumatic heart disease & 75 & 78 & 87 \\
\hline \multirow[t]{2}{*}{ D. } & $\begin{array}{l}\text { CAD: atherosclerotic and postinfarction } \\
\text { cardiosclerosis, complicated severe heart failure } \\
\text { and arrhythmias }\end{array}$ & 639 & 650 & 661 \\
\hline & CAD: unstable angina & 864 & 808 & 872 \\
\hline E. & DCMP, complicated severe heart failure & 4 & 14 & 11 \\
\hline F. & Myocarditis & 18 & 8 & 7 \\
\hline G. & Congenital heart diseases & 19 & 9 & 7 \\
\hline H. & Essential hypertension & 17 & 32 & 14 \\
\hline 2. & $\begin{array}{l}\text { Advanced COPD and renal disease, complicated } \\
\text { chronic heart failure and renal failure (cardio- } \\
\text { renal syndrome) }\end{array}$ & 24 & 14 & 14 \\
\hline & Total & 1739 & 1723 & 1785 \\
\hline
\end{tabular}

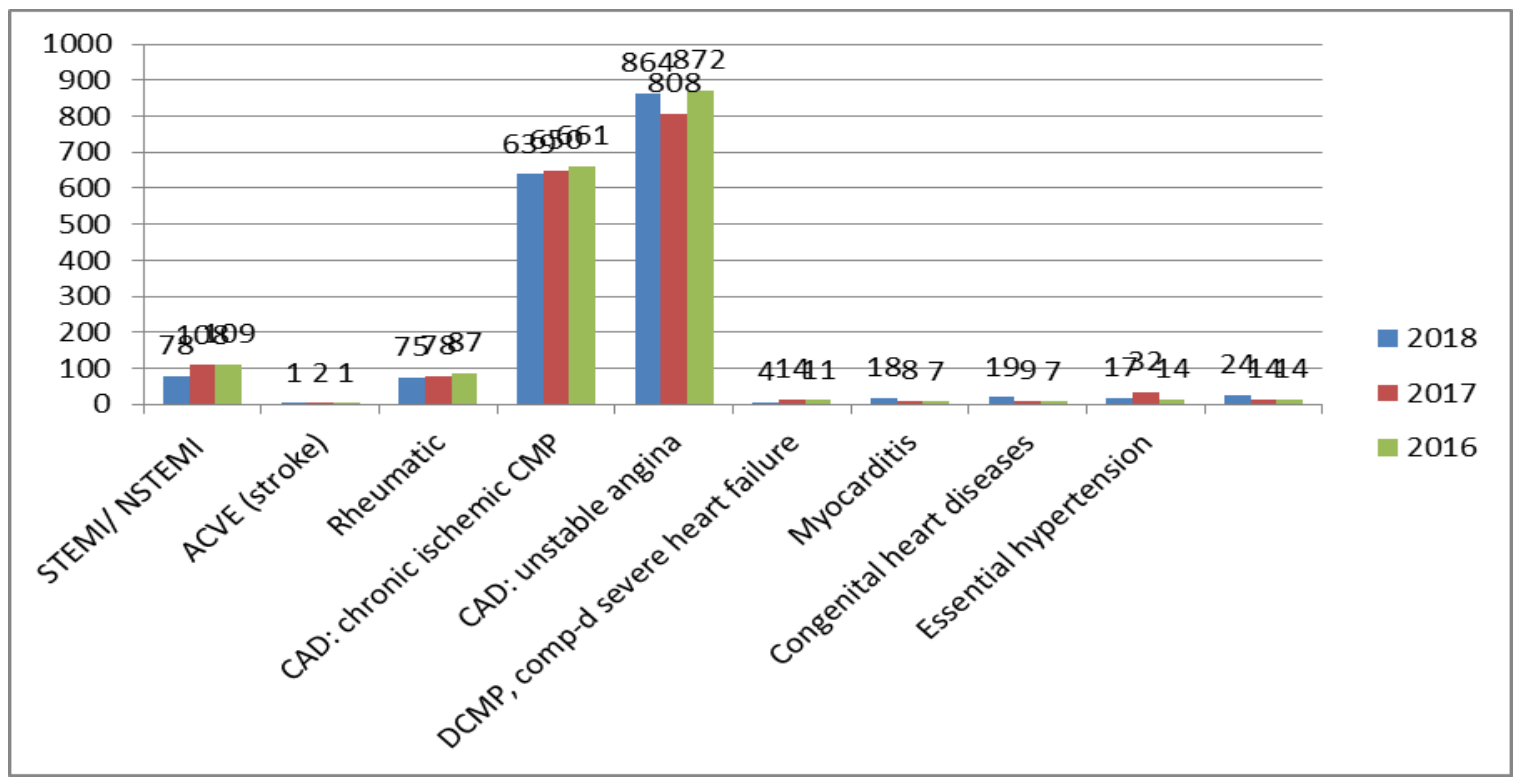

Figure 2. The prevalence of heart failure in city hospital N6 


\section{Prevalence of HF in railway station hospital}

Total number of patients in timeline 2016-2018 registered as 6809. In contrast to previous hospitals this hospital has been visited frequently. As can be seen from Table 3 and figure 3, prevalence of HF was higher in 2016. Among underlying conditions, as in previous hospitals, CAD with various forms prevailed: $91,2 \%$ of all cases for 2016, 73,5\% for 2017 and $90,7 \%$ for 2018. The total percentage of CAD was $85,3 \%$ for three years. Additionally, three cases of pulmonary embolism complicated with acute cor pulmonale was registered in three-year periods.

\begin{tabular}{|l|l|c|c|c|}
\hline \multicolumn{2}{|l|}{ Table3. The prevalence of heart failure in Railway Station Hospital } \\
\hline & Underlying conditions & $\mathbf{2}$ & $\mathbf{2 0 1 7}$ \\
\cline { 3 - 5 } & & $\mathbf{2 0 1 8}$ & $\mathbf{2 0 1 7}$ & 1 \\
\hline A. & $\begin{array}{l}\text { Pulmonary embolism complicated acute cor } \\
\text { pulmonale }\end{array}$ & 2 & 2 & 1 \\
\hline B. & Acute rheumatic endocarditis & & & 86 \\
\hline C. & Rheumatic valvular heart disease & 46 & 71 & 2562 \\
\hline D. & $\begin{array}{l}\text { CAD: acute MI, unstable angina, stable coronary } \\
\text { heart disease, chronic ischemic cardiopathy } \\
\text { (atherosclerotic cardiosclerosis) }\end{array}$ & 2477 & 775 & \\
\hline E. & Cardiomyopathies & 15 & 14 & 24 \\
\hline F. & Myocarditis & 24 & 30 & 21 \\
\hline G. & Essential hypertension & 53 & 62 & 78 \\
\hline H. & Rhythm abnormalities and conduction defects & 6 & 1 & 20 \\
\hline & Total & $\mathbf{2 7 3 0}$ & $\mathbf{1 0 5 3}$ & $\mathbf{3 0 2 6}$ \\
\hline
\end{tabular}

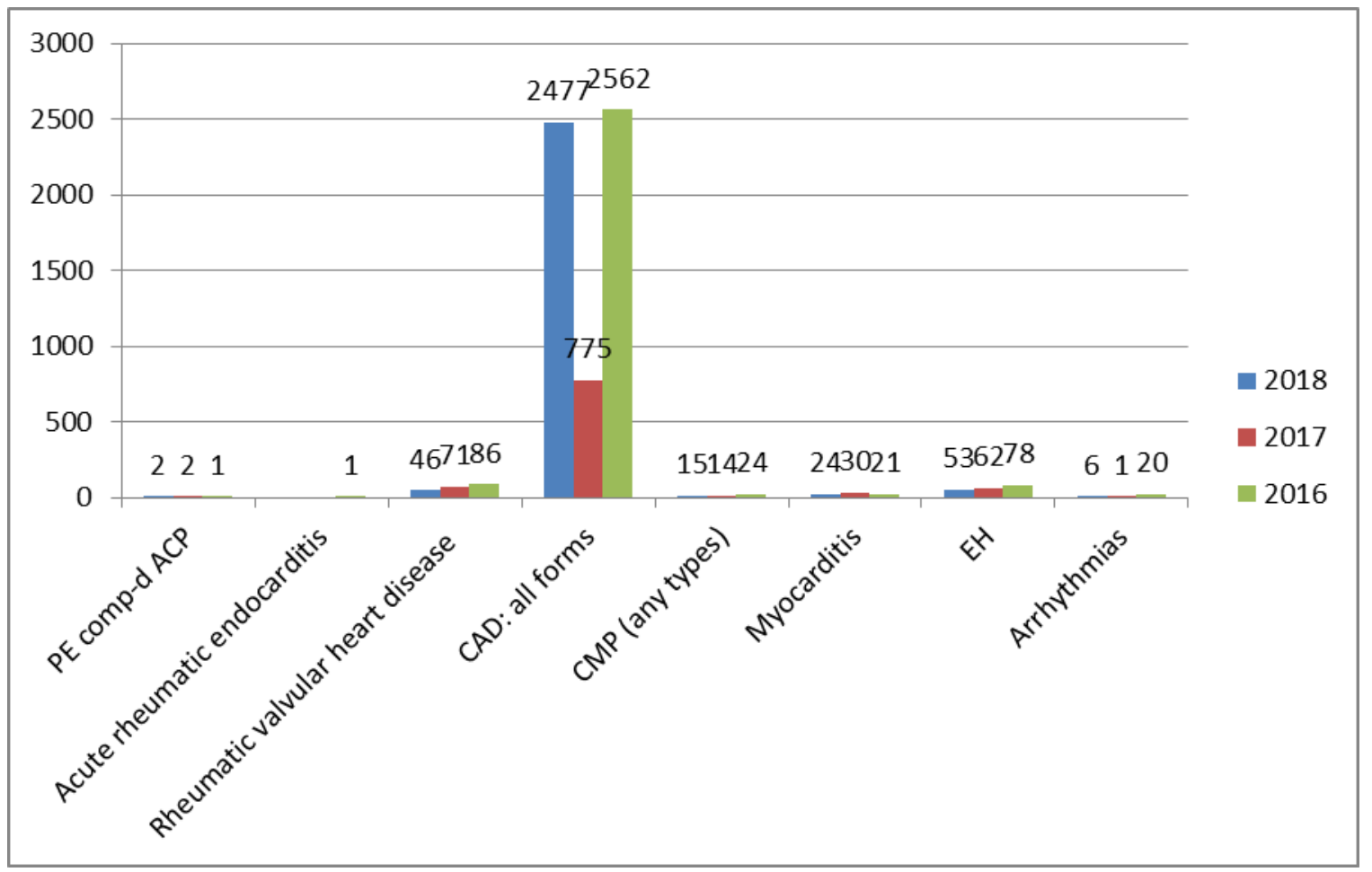

Figure 3. The prevalence of heart failure in Railway Station Hospital 


\section{Discussion}

As seen from results almost all cardiovascular diseases are complicated with heart failure. Among them ischemic etiology on the background of atherosclerosis prevails in all three hospitals. However, due to lack of organized registry we cannot completely assess heart failure burden. Only three hospital's data encompass enormous quantity of patients with heart failure, when we excluded patients of National Center of Cardiology and Cardiac Surgery Center (SRIHSOT).

Additionally, we did not obtain enough information about stage and functional class of registered patients. In this case we assumed all these patients had a NYHA class II-IV, though the real indication for therapeutic hospitalization was heart failure as a complication of underlying disease. Further studies must be dedicated to complete analysis of heart failure including age, sex, geographical regions, comorbid non-cardiovascular states and comparison off data regarding to secondary healthcare institutions with tertiary centers, such National Center of Cardiology and Internal medicine and Cardiac Surgery Center.

Peer-review: internal and external Conflict of interest: None to declare Authorship: T.Z.K, A.A.Z. and D.A.A. equally contribute to the study and manuscript preparation and fulfilled authorship criteria

Acknowledgement and funding: None to declare

\section{References}

1. Ho KK, Pinsky JL, Kannel WB, Levy D. The epidemiology of heart failure: the Framingham Study. J Am Coll Cardiol 1993; (4 suppl A): 6A-13A.

2. Ponikowski P, Voors AA, Anker SD, Bueno $H$, Cleland JGF, Cats AJS, et al, for the Authors/Task Force Members. 2016 ESC guidelines for the diagnosis and treatment of acute and chronic heart failure: The task force for the diagnosis and treatment of acute and chronic heart failure of the European Society of Cardiology (ESC). Developed with the special contribution of the Heart Failure Association (HFA) of the ESC. Eur Heart J 2016; 37: 2129-200.
3. American Heart Association. Classes of heart failure. Updated: May 8, 2017; Accessed: June 18, 2017.

4. Yancy CW, Jessup $M$, Bozkurt B, Butler D, Casey DE Jr, Drazner $\mathrm{MH}$, et al, American College of Cardiology Foundation/American Heart Association Task Force on Practice Guidelines. 2013 ACCF/AHA guideline for the management of heart failure: a report of the American College of Cardiology Foundation/American Heart Association Task Force on practice guidelines. Circulation 2013; 128: e240-327.

5. Murphy RT, Starling RC. Genetics and cardiomyopathy: where are we now?. Cleve Clin J Med 2005; 2: 465-6, 469-70, 472-3.

6. Dharmarajan K, Rich MW. Epidemiology, pathophysiology, and prognosis of heart failure in older adults. Heart Fail Clin 2017; 13: 417-26.

7. Dries DL, Exner DV, Domanski MJ, Greenberg $B$, Stevenson LW. The prognostic implications of renal insufficiency in asymptomatic and symptomatic patients with left ventricular systolic dysfunction. J Am Coll Cardiol 2000; 35: 681-9.

8. Fonarow GC, Adams KF Jr, Abraham WT, Yancy CW, Boscardin WJ, ADHERE Scientific Advisory Committee, et al. Risk stratification for in-hospital mortality in acutely decompensated heart failure: classification and regression tree analysis. JAMA 2005; 293: 572-80.

9. Levy D, Kenchaiah S, Larson MG, Benjamin EJ, Kupka MJ, Ho KK, et al. Long-term trends in the incidence of and survival with heart failure. N Engl J Med 2002; 347: 1397-402.

10. Lucas $C$, Johnson $W$, Hamilton MA, Fonarow $\mathrm{GC}$, Woo MA, Flavell $\mathrm{CM}$, et al. Freedom from congestion predicts good survival despite previous class IV symptoms of heart failure. Am Heart J 2000; 140: 840-7.

11. Maclntyre K, Capewell S, Stewart S, Chalmers JW, Boyd J, Finlayson A, et al. Evidence of improving prognosis in heart failure: trends in case fatality in 66 547 patients hospitalized between 1986 and 1995. Circulation 2000; 102: 1126-31. 